\title{
Mapping Vulnerability to Climate Change in Malawi: Spatial and Social Differentiation in the Shire River Basin
}

\author{
Jeanne Yekeleya Coulibaly ${ }^{*}$, Cheikh Mbow ${ }^{1}$, Gudeta Weldesemayat Sileshi², Tracy Beedy², \\ Godfrey Kundhlande ${ }^{4}$, John Musau ${ }^{1}$ \\ ${ }^{1}$ World Agroforestry Center, United Nations Avenue Gigiri, Nairobi, Kenya \\ ${ }^{2}$ P. O. Box 5600, Lusaka, Zambia \\ ${ }^{3} 1210$ Utica Street, Plainview, USA \\ ${ }^{4}$ World Agroforestry Centre (ICRAF), Eastern and Southern Africa Regional Programme, Chitedze Agricultural \\ Research Station, Lilongwe, Malawi \\ Email: ”. J.Coulibaly@cgiar.org
}

Received 7 April 2015; accepted 26 June 2015; published 29 June 2015

Copyright ( 2015 by authors and Scientific Research Publishing Inc.

This work is licensed under the Creative Commons Attribution International License (CC BY).

http://creativecommons.org/licenses/by/4.0/

(c) (i) Open Access

\section{Abstract}

This article analyses vulnerability to climate related shocks across five districts in the shire river basin of Malawi. The analysis employs an indicator approach that integrates biophysical and socio-economic indices. Principal component statistical analysis was used to calculate an index for adaptive capacity, sensitivity and exposure to climate impact for each of the five districts. These indices were aggregated to develop a vulnerability index differentiated also by gender for the surveyed districts. The results showed that Chikwawa, Machinga and Blantyre appear to be more vulnerable to climate related shocks compared with Mwanza and Zomba. Women in Chikwawa are also found to be the most susceptible to the climate hazards impacts. To reduce vulnerability to climate impact, the study suggests that the national adaptation strategies adopted by the government should be mainstreamed into specific local adaptation actions that can be accessible and adopted by the community. Specific emphasis should be given to the improvement of women's welfare through better access to productive assets and resources.

\section{Keywords}

Climate Change, Vulnerability, Principal Component Analysis, Malawi, Shire River Basin

\footnotetext{
${ }^{*}$ Corresponding author.
} 


\section{Introduction}

The agriculture sector in Malawi as in most African countries is dependent on rainfall. This high dependence on the short rainy season renders the country very vulnerable to weather hazards. Erratic rainfall, increased water scarcity, rising temperatures, and extreme weather events such as floods and droughts have increased in magnitude and frequency. In January 2015, the country experienced an unprecedented flood hazard that disrupted millions of livelihoods in central and southern Malawi [1]. The higher frequency of flood and drought represents a big threat for the economy and populations' livelihoods because of the many consequences on agricultural production, food security, water availability and health [2].

The country is also affected by other environmental challenges especially deforestation and land degradation. Deforestation through conversion to farmland, slash and burn agriculture, charcoal burning, bush fires and harvesting of wood (for tobacco curing, smoking fish, timber, poles, etc.) is a key driver of forest cover change. The forest cover in Malawi has declined from 3.9 million ha in 1990 to 3.2 million ha in 2010, with an annual deforestation rate of almost 1\% during the period 2005-2010 [3], one of the largest in the eastern half of Africa. Yaron et al. (2011) [4] showed that soil losses averaged $20 \mathrm{~T} / \mathrm{ha} / \mathrm{year}$, which translated in a yield loss of $4 \%$ - 25\% loss every year. The creeping effects of soil erosion and deforestation undermine further the livelihoods of rural communities and exacerbate the extent of food insecurity and rural poverty in Malawi. Loss of fertile soil also has several negative impacts on water cycle, biodiversity and supportive ecosystem services.

The high exposure of Malawi to climate change and environmental stresses has sparked the interest of development agencies and research institutions to report evidences of the occurrence of these environmental challenges and explore their impact on agriculture. Climate change impact studies in Malawi to date have predominantly been focused on biophysical aspects with attention been given on the crop yield and livestock production impact. The current knowledge showing that Malawi is a vulnerable country is primarily based on the biophysical responses to climate change using global climate models.

But it is increasingly recognized that vulnerability cannot be solely understood by the assessment of the biophysical impact [5]-[7]. There is a need for more comprehensive and holistic approaches that integrate both biophysical and socio-economic impacts. In this paper, in addition to looking at the biophysical component of vulnerability, we will explore the socio-economic conditions that affect the ability of households in Malawi to cope with climate change and land degradation. As stated by [8], understanding the different dimensions of vulnerability is a prerequisite for the design and implementation of adaptation policies that will promote equitable and sustainable development. The Malawi National Adaptation Programme of Action (NAPA) established that the Shire basin was vulnerable to climate variability and change [9]. However, there is a significant knowledge gap regarding the spatial variation in vulnerability among different communities. Our hypothesis is that significant variation in vulnerability exists among different parts of the Shire basin and also among genders. Therefore, the objective of this study is to assess the spatial and gender differentiation aspect of vulnerability to the environmental hazard at the district scale in southern Malawi. Such analysis will be essential for policy decision making to reduce geographic development imbalances and empower the most vulnerable in farmers 'communities in Malawi.

\section{Methods}

\subsection{Study Area and Data Source}

\subsubsection{Study Area}

The study was conducted in the southern region of Malawi, precisely in the Shire River Basin. The Shire is the largest river in Malawi. It forms the outlet for Lake Malawi and is a trans-boundary river in the Zambezi basin, passing through the Republic of Mozambique to the Indian Ocean. The Shire River Basin covers 16\% of Malawi's area with $22 \%$ of the population [10]. This river basin is divided into three sections: i) The Upper Shire being the exit from Lake Malawi and the relatively flat topography around Liwonde; ii) The Middle Shire is characterized by the steep topography either-side of the gorges around the river, leading to hydro-power barrages and power stations, and iii) The Lower Shire encompasses the flat altitude floodplain wetland system with marshes of wildlife-biodiversity significance, a major sugar estate, cotton fields, cattle ranches as well as smallscale subsistence agriculture. Administratively, the Shire River Basin is divided in to eight districts falling under three Agricultural Development Divisions (ADD), namely, Machinga ADD, Blantyre ADD and Ngabu ADD. Machinga ADD covers Machinga, Zomba and Balaka districts. Blantyre ADD includes Chiradzulu, Blantyre, 
Mwanza, Neno, Thyolo, Mulanje and Phalombe districts. Ngabu ADD is divided into Chikwawa and Nsanje districts. Annual population growth rate is the highest in the Blantyre ADD with growth rates ranging from $1 \%$ in Blantyre rural to 4\% in Mwanza. In the other two ADD, annual population growth rates are comprised between $2 \%$ and $2.9 \%$ [11].

The Shire River Basin is characterized by the highest prevalence of poverty within Malawi [12] and a rural economy based on small scale subsistence and rainfed farming systems. Rainfed agriculture accounts for almost half of the land area [11]. In all ADD, maize is the dominant crop and is intercropped with vegetables, beans, groundnuts and other cereals including millet, sorghum. Irrigated agriculture is practiced both at subsistence level and large-scale agriculture including estates. Irrigation on estates is used for growing tobacco seedlings, coffee, sugarcane and other crops. Unsustainable agricultural systems have resulted in massive land degradation marked by soil erosion, and sedimentation of rivers and wetlands which increase vulnerability to climate change. The shire river basin is described as being vulnerable to climate change and variability. Scientific evidences underscore a shift in the river basin climate toward more and intense drought, erratic rainfall pattern, flooding and a mean temperature increase [13].

\subsubsection{Data Source}

This study uses primary data collected from a household survey conducted in the Shire River Basin in 2009 under the Land Capability and Suitability project and secondary longitudinal rainfall and temperature observations from 1972 to 2009. Primary data were collected using a stratified random sampling design. First, the five districts targeted under the Land Capability and Suitability project were purposively selected to capture diverse climate and environmental challenges in the Shire River Basin. Then, in each district, one Extension Planning Area (EPA) was randomly selected, namely Ntubwi, Chingale, Kumthembwe, Mwanza, and Mitole located in the districts of Machinga, Zomba, Blantyre, Mwanza and Chikwawa, respectively. A structured questionnaire was administered to a sample of 30 households randomly selected in each EPA, leading to a total of 150 individual households interviewed. Data gathered included household demographics, food and agro-forestry practices, sources of income, soil fertility, access to extension services, livelihood assets, and climate change issues. Climate change information was related to households' perceptions of a change in the frequency and severity of drought, flood, soil erosion, change in the length of the growing season and the onset of the rainfall season.

Besides individual household survey, key informants and stakeholder consultation were also conducted to identify the most important of the environmental problems in the districts surveyed. Data on historical rainfall, minimum and maximum temperature over the period 1972-2009 was collected from weather stations in the targeted districts. This paper also uses information on extreme events obtained from the national disaster department for the time span mentioned earlier.

\subsection{Conceptual Framework for Analyzing Vulnerability}

There have been many attempts in the literature to define vulnerability to climate hazards with an initial focus on the natural hazard or the physical environment [14] and then by extending this concept to include the human dimension or socio-economic condition of a group of individuals that affect their ability to adjust or cope with the environmental stress. These definitions often express similar ideas with some terminologies that overlap in their meanings or concepts that are sometimes opposites [15] [16]. Given this plurality of definitions, the concept of vulnerability used in this study will rely on the most popular definition provided by the Working Group II of the Intergovernmental Panel on Climate Change (IPCC). So, in the Third Assessment Report (TAR) of the IPCC, vulnerability is defined as "the degree to which a system is susceptible to, or unable to cope with adverse effects of climate change, including climate variability and extremes. Vulnerability is a function of the character, magnitude and the rate of climate change and variation to which a system is exposed, its sensitivity and its adaptive capacity” [17].

In this definition, the first key parameter is exposure, which refers to the stress that impacts a system; it is the extent to which a system is exposed to the climate hazard. The second key parameter is sensitivity representing the system's condition that can reduce or worsen the impact. The third one is adaptive capacity corresponds to the human ability to resist or adjust to the stress impact. Exposure and sensitivity, represent the potential impact while adaptive capacity is the extent to which a community can cope with the risk and avert the impact of the hazard. From these three dimensions of vulnerability and accounting for the interactions among these dimen- 
sions [18], designed an integrated conceptual framework that includes the coupled human-environment systems with multiple and complex linkages. The authors stressed that vulnerability is revealed through the sensitivity of the system to any exposure. This sensitivity is determined by the interaction between the social (human) and bio-physical capitals (environment) and should be place specific. Following this framework, this paper refers to vulnerability to climate change to the interaction between the social and bio-physical sub-systems in the spatial scale of southern Malawi. If the natural environment is exposed and sensitive to the climatic hazard and the human capacity including the institutional mechanisms are limited to cope with the impact of the climate shock, then vulnerability will be high. So, vulnerability increases with the potential impact of the hazard on a community but decreases with high adaptive capacity. It is expressed mathematically as potential impact $(I)$ minus adaptive capacity $(A C)$. The expression is formulated as follows:

$$
V=f(I-A C) \text {. }
$$

This expression shows us that large (low) adaptive capacity diminishes (heighten) the impact of the hazard on a community which as a result becomes less (more) vulnerable.

\subsection{The Indicator Approach of Vulnerability Assessment}

Vulnerability refers to various underlining concepts that relate in most instances to qualitative aspects of livelihood (e.g. sensitivity, adaptive capacity). Therefore, translating the concept of vulnerability into a single indicator or measurable parameters raises big methodological challenges. Several approaches can be used to operationalize vulnerability to climate change but the most common method is the indicator approach. This approach is useful for monitoring trend, evaluation, allocation of priorities for intervention and to develop policies that can improve resilience and facilitate adaptation [19]. In the indicator approach, quantitative assessment of vulnerability is realized by constructing a "vulnerability index". The index is a composite indicator based on a set of indicators, proxy variable for vulnerability or aggregated indicators that form indices and measure vulnerability.

Several studies strived to develop indicators and indices to assess vulnerability at different scales from household to national scale but most empirical studies have tended to focus on sub-national (regional) level. Cutter et al. (2003) [20] developed an index of social vulnerability to environmental hazards by using county level socio-economic and demographic data from the United States. O’Brien et al. (2004) [21] constructed vulnerability profile to climate change for India at a regional scale by combining indices for adaptive capacity with sensitivity indices that encompasses exposure to climate change.

Other studies have been conducted to quantify vulnerability at household and national levels [22]-[24]. Most national levels vulnerability studies consisted at comparing different countries to identify hotspots where development actions are most needed. Moss et al. (2001) [22] developed proxy variables and indicators to undertake vulnerability analysis that integrated both environmental and social perspective. Those indicators helped to identify countries or group of countries that are particularly vulnerable in order to prioritize policy interventions in those countries. At individual scale, [23] investigated vulnerability in northern Vietnam by using an indicator of absolute poverty which measures social vulnerability. The reason supporting the choice of this indicator is that the poor are often discriminated against access to resources rendering them intrinsically more vulnerable. More recently, [24] used an indicator approach to investigate household vulnerability to climate change and identify the factors affecting vulnerability of households in Swaziland. This approach permitted to classify households based on their level of vulnerability and to formulate differentiated policy actions to address households' needs.

Selection of the vulnerability indicators is generally derived from the literature particularly from bio-physical simulation models [22] for the bio-physical sub-component and on the sustainable livelihood approach [25] for the social sub-component. The sustainable livelihood approach relates to a combination of livelihood resources called capital (natural, economic, physical, human) that enable a livelihood to cope, recover from stress and shocks. The sustainable livelihood approach is based on Sen's entitlement theory where entitlement represents the actual or potential resources available to individuals based on their own production, assets or reciprocal arrangements [26]. Hence, vulnerability could leads to a differentiation between resources-endowed communities with resources-constrained communities. In reality, there are many transitions between the two ends, between the less and the more vulnerable groups. Additionally it is important to recognize that vulnerability does not refer to a static situation of social weakness, it translates to a number of processes that can result to increase or re- 
duce vulnerability depending to exposure and social dynamics. To monitor such changing situations it is important to have a suited set of indicators and in this study, selection of the indicators was guided by the approach used by [6] which integrates both indicators from sustainable livelihood and the bio-physical conditions of farmers. The final set of indicators selected was dictated by data availability.

\subsubsection{Exposure}

The exposure indicator used to construct households' vulnerability profile is related to the biophysical factor. The characteristics of the stress factor include its magnitude, frequency, duration and areal extent of the hazard [27]. For this study, households' frequency of extreme events, rate of changes in minimum maximum temperature, and the average annual precipitation over the period 1972-2009 for the selected districts as indicators of exposure. Such variables are indicators of the extent of the climate stress they incur and will help determine which individuals and areas are more exposed to climate impacts and are at higher risk. Malawi has a history of climate disasters which can be traced back to the 1991/1992 southern Africa drought. Since this period, disasters have escalated with serious drought in 2002, followed by another drought in 2004/05. Before 2001, only nine districts in Malawi were classified as flood-prone. In 2001, 16 were affected, and a further 14 in 2002 . By the end of January 2003, there was localized flooding in 22 districts, causing eight deaths and damaging homes and crops. These frequent droughts and floods have led to significant soil erosion undermining crop productivity. Vulnerability is expected to increase with an increase in the frequency of extreme climate events, and rate of changes in the temperature and rainfall.

\subsubsection{Sensitivity}

The sensitivity indicator is closely related to the perceived condition of the natural resources on which households depend [28]. The sensitivity indicator selected includes households' perception of soil fertility, their perception of change in their unproductive land, and their experience with crop failure over the past five (5) years. As agriculture is a primary source of food supply and income in the communities surveyed, poor land quality and increasing proportion of unproductive land will worsen the impact of climate change and increase households 'sensitivity to the change in climate related events. Poor soil fertility caused by nutrients losses as a result of climate stressors and low supply of fertilizer dampens the magnitude of the negative impact of the disaster. Households with fertile lands are expected to be less sensitive to the extreme climate events and less vulnerable. Higher share of unproductive land is often the result of the impact of past climate disasters and increases the susceptibility of the system to the climate risks by having an adverse effect on crop production. Experience of crop failure is largely influenced by climatic factors [29] and therefore demonstrates that the cropping system is sensitive to climate hazards.

\subsubsection{Adaptive Capacities}

Households' adaptive capacities depend on their socio-economic characteristics. A same shock may have different impact within a same community depending on households' economic and social conditions. The climate change literature has identified numerous socio-economic characteristics that influence vulnerability. The sustainable livelihood framework is used for this study to derive indicators for adaptive capacity. We categorized the factors that influence households' ability to adjust to climate hazards or to cope with the climate change impacts into four livelihood assets that are social capital, human capital, physical capital and financial capital. The specific factors include education, age, farm income, land area, access to extension services, number of family members, farm income, housing quality and wealth assets, as identified by the climate change literature [7] [20] [21] [30]. The human capital is represented by the education level of the household head and access to extension services. The variable education level provides basic information on individuals' ability to understand technical aspects of climate information that can improve their decision making and also to embrace a diverse range of technological and economic opportunities to enhance their livelihoods. Lower education level limits the ability to understand technical information [20] and to effectively have access and use climate information pertaining to early warning systems, forecast that are conveyed on reading materials and in non-local languages [31]. Through access to extension services from government officials, NGOs, project, households benefit from information about climate services and climate smart technologies that can strengthen their ability to better cope with climate risk. Results from [31] study suggest that extension agents are very effective in providing vulnerable populations 
information about climate and support services that they need to build their adaptive capacities, provided those extension agents are themselves well-trained. So, lack of access to extension services can be perceived as an indication of poverty and vulnerability. Indeed, poor people are often located in marginalized areas barely accessible to extension agents.

Number of family members contributes to social capital formation [32] which plays a determinant role in reducing transaction costs, facilitate information flow, and increasing trust [33]. Besides, larger family size provides the labour resources needed to perform farm activities and raises the productivity of factor of production. Yet, some other studies argued that large family size may actually have limited financial resources to meet the household obligations which will negatively impact resilience and recovery from natural hazards [20] [34]. Thus, the number of family members might have an ambiguous effect on vulnerability.

Physical capital is represented by housing quality. Good quality of housing provides safety and ensures physical well-being during extreme climate events [7]. Adequate housing minimizes the risk of losing the households' productive assets (cash/saving, agricultural and household equipment) essential to their livelihoods. Households with poor housing type are at high risk of being affected by climate hazards. Also, housing quality reflects the economic status of an individual or a family. Poor households are often those living in precarious housing conditions. In our study, housing quality refers to the type of roof made with grass, iron sheet or asbestos.

Financial capital in this study includes land area and farm income. Land area is a proxy for farm income. The larger is the area cultivated and the greater is the households' potential to generate higher farm income. Farm income provides smallholder farmers with the funds and assets necessary to seize the economic opportunities for adaptation to climate variability and land degradation. Empirical research on climate stress on agriculture showed that income and wealth are important in coping strategies [29] [35]. Higher income enables households to absorb and recover from losses more quickly [5] [20].

\subsubsection{Constructing the Vulnerability Index}

Construction of the vulnerability index relies in the aggregation of a set of selected indicators for each of the three components of vulnerability i.e. exposure, sensitivity and adaptive capacity. Since the indicators are in different units and scales, we followed the methodology used by UNDP's Human Development Index (HDI) [13] and applied by several authors including [7] to normalize them. Normalization ensures that all values fall between the range of 0 and 1 by applying the following formula:

$$
x_{i j}=\frac{X_{i j}-\bar{X}_{i}}{\sigma_{i j}}
$$

where $x_{i j}$ represents the observed value of the variable (indicator), $\bar{X}_{i}$ represents the mean value of the indicator and $\sigma_{i j}$ the standard deviation for each indicator. Next, we assign some weights to the indicators by using the Principal Component Analysis (PCA) [6] [30] [36] [37]. PCA is the preferred method to assign weights to the indicators since finding weights through expert judgment [38] has often been criticized for being too subjective and lack consensus among experts while using arbitrary choice of equal weight appear to be too arbitrary and may not capture the relative importance of the indicator on vulnerability [7].

Following the procedures described by [37] and [6], the factor loadings or scores from the first component of PCA, which accounts for the largest variability in the data set, are considered as weight for the indicators. These factor loadings measure the extent to which each indicator contributes to the resulting principal component and provide information to the drivers of vulnerability.

Separate indices for exposure, sensitivity and adaptive capacity are constructed by multiplying the normalized variables with the specific weight assigned to each indicator. The indicator is an integral of all normalized indices. The formula is as follows:

$$
I_{j}=\sum_{i=1}^{k} b_{i}\left[\frac{a_{j i}-x_{i}}{s_{i}}\right]
$$

where $I$ is the respective index for each component (exposure, sensitivity, adaptive capacity) of vunerability for each household $j ; b$ refers to the weight assigned to each indicator from the first principal component; $a_{j i}$ is the indicator value for each household $j$; $x_{i}$ is the mean indicator value and $s_{i}$ is the standard deviation of the indicators. 
The vulnerability index is calculated for each specific household and then aggregated at the district level. It is calculated as the linear combination of exposure, sensitivity and adaptive capacity as follows: $\mathrm{V}=\mathrm{E}+\mathrm{S}-\mathrm{AC}$ where $\mathrm{V}$ is the vulnerability index, $\mathrm{E}$ is the exposure index and AC the adaptive capacity index.

\section{Results and Discussions}

PCA are run separately for the three components of vulnerability, exposure, sensitivity and adaptive capacity. Results of the factor loading for the first principal components of the exposure, sensitivity and adaptive capacity indices along with the mean and standard deviation of the original variables are reported in Table 1 below. The first principal component of these indices accounts for the greatest variation in the data sample and explains $49 \%, 46 \%$ and $25 \%$ of the variance in the exposure, sensitivity and adaptive capacity variables, respectively. Larger weights are given to the indicators that vary most across households and districts. In the exposure index, frequency of climate extreme and rate of change in rainfall have the highest and positive loadings. This indicates that these later variables contributes more and positively to the exposure index than the temperature variables. In the sensitivity index, the variables with the largest weights are experience of crop failure and rate of change in land degradation. The indicators of adaptive capacity that are contributing largely to the adaptive capacity index are farm income, education of the household head, rate of change in area cultivated.

The index scores for sensitivity, exposure and adaptive capacities for each individual household were aggregated at the district level and represented in Figure 1.

From Figure 2, the exposure index shows that Chikwawa is the most exposed to climatic shock, and is followed by Zomba and Machinga. Mwanza and Blantyre districts are the least confronted to climate and environmental hazards. These results are very consistent with expectations. The district of Chikwawa falls completely within the catchment of the shire river and as a matter of fact, is highly exposed to the river flow variation. Communities interviewed in the districts of Machinga and Zomba are located in the lake Chilwa and Phalombe

Table 1. Factor loading, and descriptive statistics of the indicators.

\begin{tabular}{|c|c|c|c|c|}
\hline & Variable description & $\begin{array}{l}\text { Factor } \\
\text { scoring }\end{array}$ & Mean & $\begin{array}{l}\text { Standard } \\
\text { deviation }\end{array}$ \\
\hline \multicolumn{5}{|l|}{ Exposure index } \\
\hline Frequency of extreme events & Number of extreme events & 0.616 & 5.000 & 1.099 \\
\hline Minimum temperature & Rate of change in average minimum temperature & -0.533 & 0.038 & 0.019 \\
\hline Maximum temperature & Rate of change in average minimum temperature & -0.340 & 0.025 & 0.017 \\
\hline Change in rainfall & Rate of change in average minimum temperature & 0.470 & 0.170 & 0.340 \\
\hline \multicolumn{5}{|l|}{ Sensitivity index } \\
\hline Soil fertility & $\begin{array}{l}\text { Perception of households regarding their soil fertility, } \\
\text { dummy variable } 1=\text { good and } 0=\text { bad }\end{array}$ & -0.632 & 0.513 & 0.501 \\
\hline Experience of crop failure & $\begin{array}{l}\text { Experience with crop failure over the last } 5 \text { years past 2009, } \\
\text { dummy variable, } 1=\text { yes, } 0=\text { no }\end{array}$ & 0.586 & 1.733 & 0.444 \\
\hline Change in land degradation & $\begin{array}{l}\text { Perception of households regarding change in degraded land, } \\
\text { categorical variable } 1 \text { = decrease, } 2 \text { = no change, } 3=\text { increase }\end{array}$ & 0.508 & 2.160 & 0.868 \\
\hline \multicolumn{5}{|l|}{ Adaptive capacity index } \\
\hline Technical assistance & Access to technical assistance, dummy variable $1=$ yes, $0=$ no & 0.286 & 0.780 & 0.416 \\
\hline Farm income & Total farm income in Kwacha & 0.607 & 8259.97 & 15629.63 \\
\hline Change in area cultivated & $\begin{array}{l}\text { Perception of households regarding change in area cultivated, } \\
\text { categorical variable, } 1 \text { = decrease, } 2 \text { = no change, } 3 \text { = increase }\end{array}$ & 0.414 & 2.093 & 0.822 \\
\hline Education of household head & $\begin{array}{l}\text { Education of the household head, categorical variable, } \\
\qquad 1 \text { = none, } 2 \text { = primary, } 3 \text { = secondary }\end{array}$ & 0.451 & 1.953 & 0.606 \\
\hline Family size & Family size, number & -0.064 & 4.607 & 1.996 \\
\hline Roof type & Roof type with leaves, dummy, $1=$ yes, $0=$ no & 0.414 & 1.209 & 0.408 \\
\hline
\end{tabular}




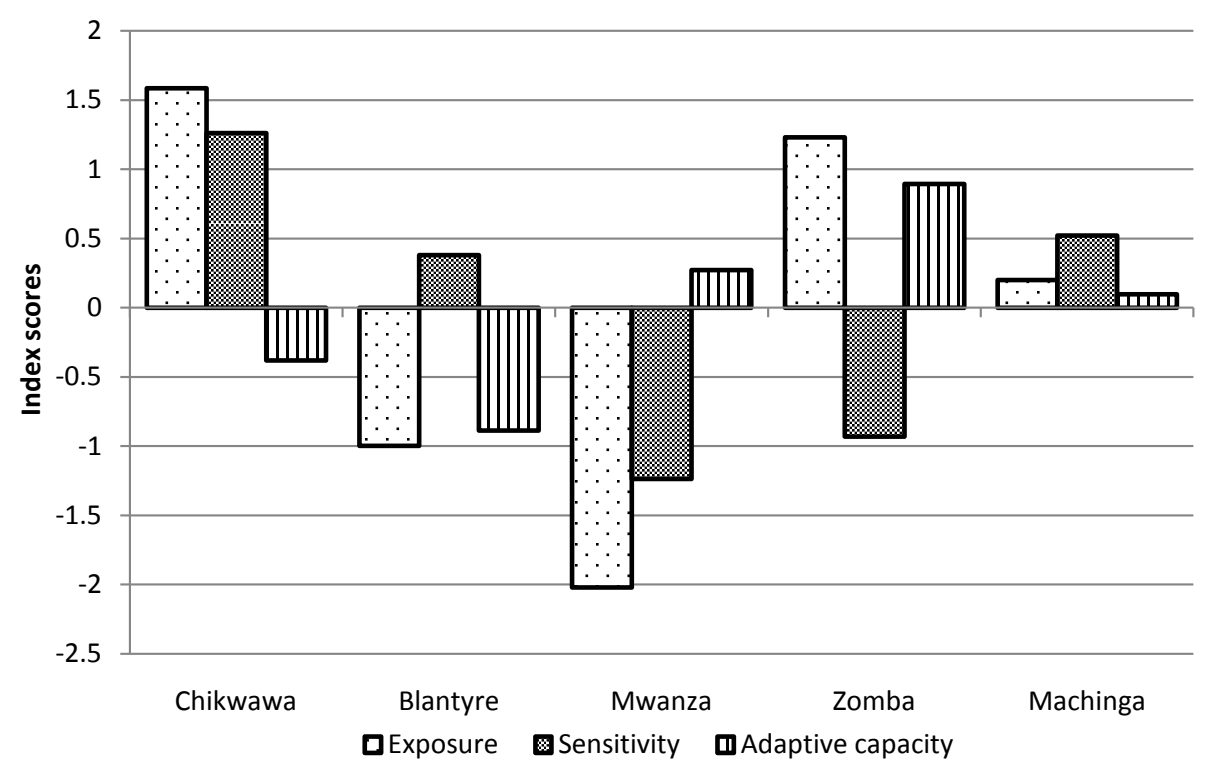

Figure 1. Index scores for sensitivity, exposure and adaptive capacities across districts.

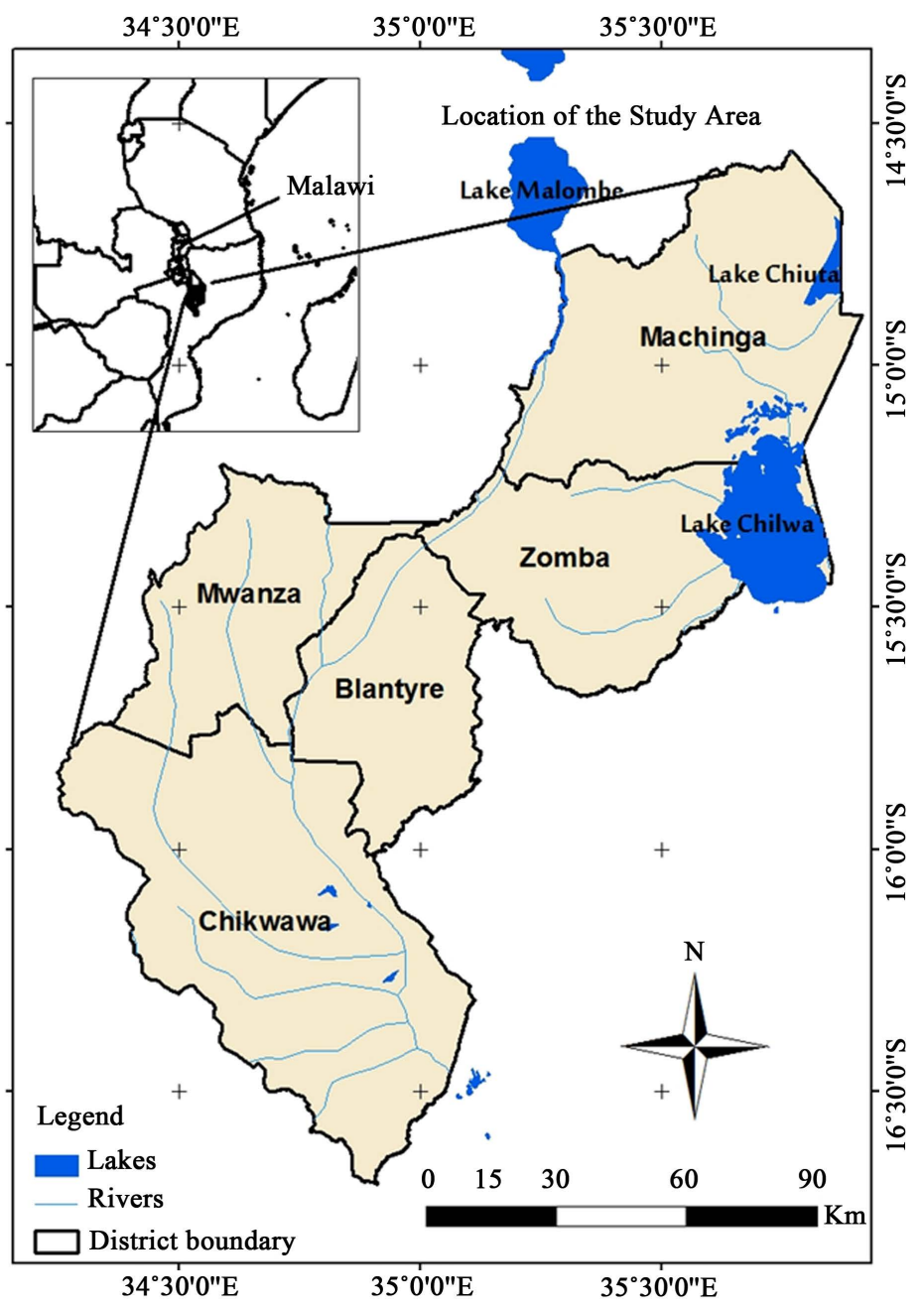

Figure 2. Map of study sites (authors’ own design). 
plain livelihood zone. This area is surrounded by the lakes Chilwa and Chiuta and receives an annual rainfall of 700 to $1000 \mathrm{~mm}$ [39]. The rivers tend to drain in this flat land exposing the populations to frequent floods that cause loss of life and property. Respondents interviewed in Mwanza and Blantyre were from the EPAs of Mwanza and Kumthembwe which are located in the middle shire valley. This area extends from the southern end of Lake Malombe in the north to the Mpatamanga gorge in the south. The zone has a relatively dry climate with a mean annual precipitation ranging from 200 - 1000 millimetres [39]. As a matter of fact, dry spells which causes frequent damage to crop particularly maize production is the main hazard encountered in the area.

For the sensitivity index, Chikwawa is still by far the most sensitive district. Indeed, in terms of bio-physical characteristics, the district of Chikwawa, part of the administrative agricultural region (ADD) of Ngabu, is characterized by the lowest proportion of good quality land compared to the other districts; this proportion is estimated at $14 \%$ [40]. Most of the good quality and moderate quality land is already intensively cultivated, and scope for expansion is very limited. Further, the nutrient status of most cultivated soils is low with widespread deficiencies of nitrogen and phosphorus. Zomba and Machinga located in Machinga ADD are the next most sensitive districts in this study. Although the Machinga ADD has in general a significant proportion of good quality land, with $41 \%$ of land area classified as good quality land for rain-fed agriculture [40], the EPAs surveyed are characterized by infertile poor soils leading to production shortfalls. Indeed the high sensitivity indices of these districts were mainly driven by the crop failure variable. Besides, the year 2009 of data collection was a poor crop year due to heavy rainstorm which led to severe crop damage in Zomba and Machinga. The districts of Blantyre and Mwanza are the less sensitive to climate shocks. The use of subsidized fertilizer to improve soil and crop productivity is most common in these districts than in the other areas of the shire river basin [41].

Regarding the adaptive capacity, the results show that Blantyre and Chikwawa have the weakest capacities to adapt consistently with expectation. Blantyre and Chikwawa are the poorest neighbor districts in southern Malawi. They face numerous problems including food insecurity, high illiteracy rate, poor access to safe water and sanitation, high prevalence of HIV/AIDS [9]. On the other hand, Zomba, Mwanza and Machinga have higher ability to cope to climatic risk compared to the two previous districts as revealed by their larger adaptive capacity indices. This is consistent with [41] findings that communities in the lake Chilwa and Phalombe Plain zone as well as in the Middle Shire Valley have the highest education level, physical and natural capital in southern Malawi. So, in the event of a climate shock these communities are better equipped to resist and adjust to the adverse conditions and will suffer less.

The overall vulnerability index combines the three indices developed above. Higher positive value of the index indicates that the district is more vulnerable while lower negative value means that the district is relatively less vulnerable compare to the others.

The results of the cluster analysis represented in Figure 3 indicate three categories of vulnerability. The first category includes the districts with the highest vulnerability indices. These districts are Chikwawa and Machinga. Chikwawa is by far the most vulnerable with an index value of 3.22 (Figure 1). High exposure of this district to climate variability and soil degradation coupled with low resilience abilities render this district highly vulnerable. Machinga is the second most vulnerable district with an index value of 0.62 , mainly triggered by the high sensitivity and exposure of this district to adverse climatic events. The second category includes the districts with medium vulnerability index and has only one district, Blantyre. This district has a vulnerability index of 0.27 largely due to the high sensitivity of this district to adverse climatic events. The third group encompasses the districts that have the lowest vulnerability indices. This consists of the districts of Mwanza and Zomba, with the vulnerability indices estimated at -3.53 and -0.59 , respectively. Mwanza was the least vulnerable to climate change, owing to the low sensitivity index. Indeed, although Mwanza is exposed to the impact of extreme climate conditions, it shows some potentialities to adapt but more significantly agricultural systems in this district have a very low sensitivity levels to climate and environmental degradation.

In all districts, female headed households were the most vulnerable as shown by their lower index score values (Figure 4). But, the t test comparing the mean values between men and women revealed that the difference in the level of vulnerability between those two groups is only significant in the district of Chikwawa (Table 2). The other districts do not portray a significant difference in the level of vulnerability across gender. Women being most vulnerable are also consistent with expectation since they face many barriers to increase farm productivity including land access, farm equipment, labour, and cash/credit. 


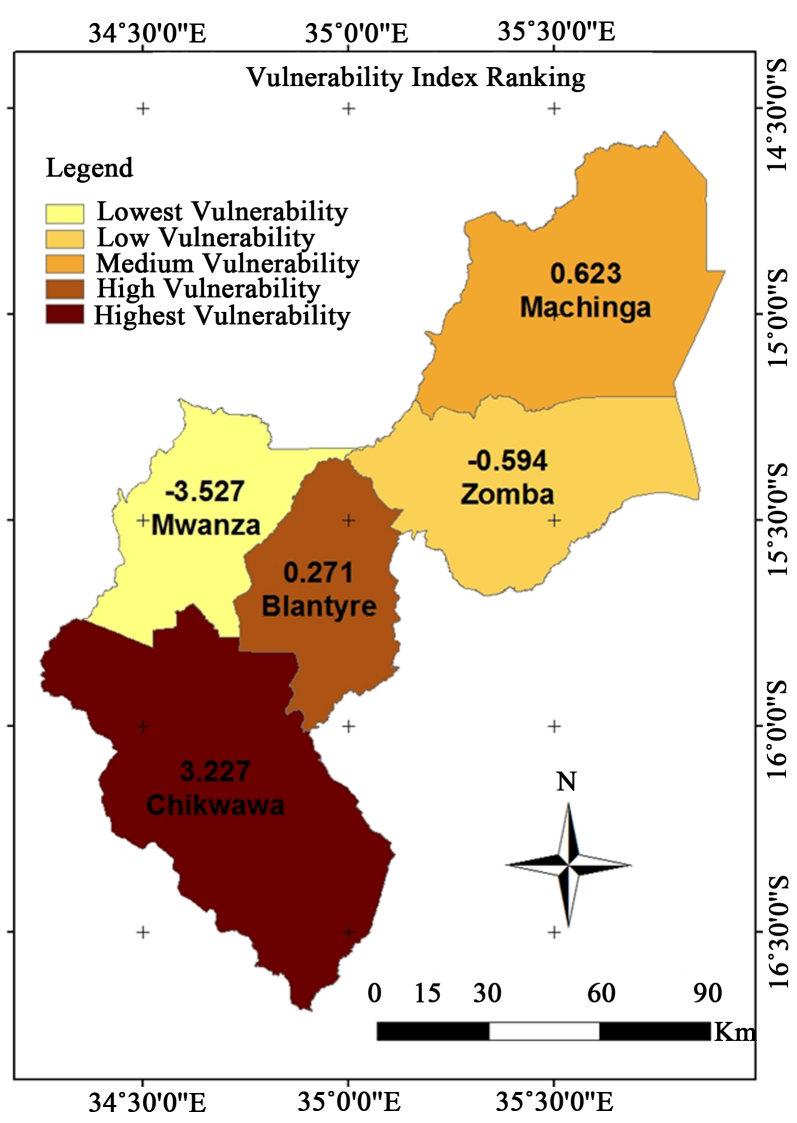

Figure 3. Map of vulnerability across districts.

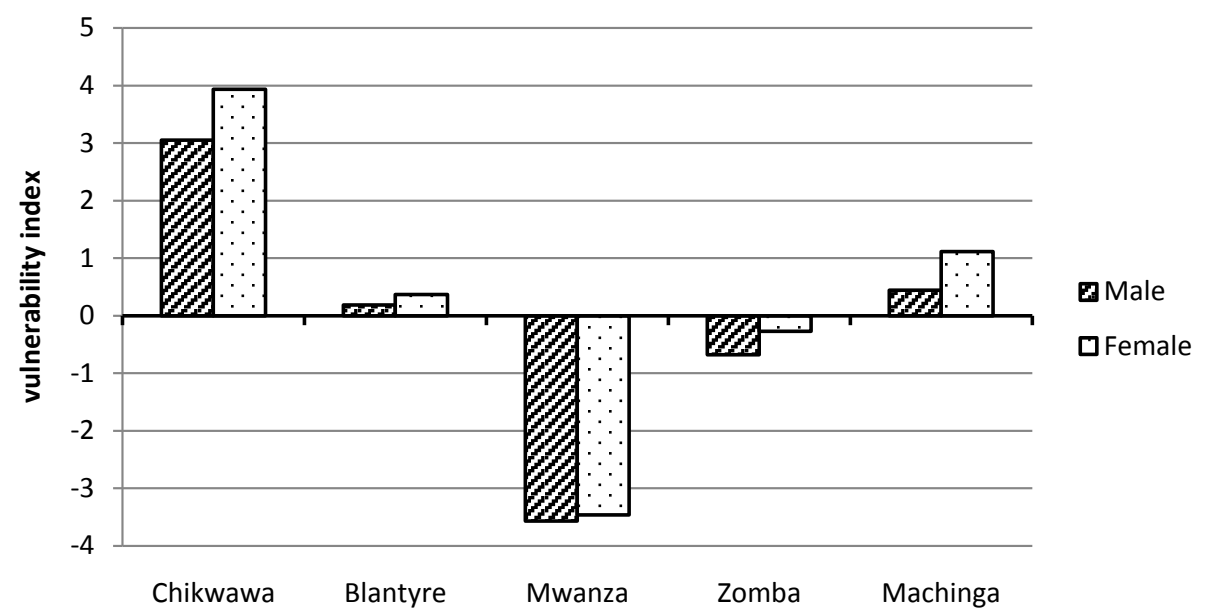

Figure 4. Vulnerability scores across gender in districts.

Table 2. Statistical difference in vulnerability status between men and women.

\begin{tabular}{cccccc}
\hline & Chikwawa & Blantyre & Mwanza & Zomba & -0.68 \\
Men & 3.05 & 0.19 & -3.57 & -0.44 & 1.12 \\
Women & 3.93 & 0.37 & 0.27 & 0.41 & 0.10 \\
Difference & $0.88^{*}$ & 0.18 & 0.46 & \\
\hline
\end{tabular}

*Statistical significance at $10 \%$ level of confidence. 


\section{Conclusions and Policy Recommendations}

Malawi is characterized by endemic poverty and high susceptibility to frequent and unpredictable weather shocks. In this context, this research study provided a unique opportunity to assess vulnerability in southern Malawi and guide policy makers in the development of action plans to anticipate disasters and assist communities to adapt to the adverse impacts of hazards. Vulnerability was analyzed using an indicator approach, principal component analysis that integrated the three components of vulnerability.

Results show that sensitivity and adaptive capacities play a major role in the vulnerability status of households and districts. To reduce sensitivity and enhance adaptation to climate extremes, the government of Malawi has developed the NAPA programme [9] that includes relevant options such as afforestation and re-afforestation to control siltation, to provide fuel wood and to represent an alternative source of cash income. This technology has also the advantage to enhance soil fertility and increase crop productivity. Other government solutions suggested include provision of irrigation services, farmers' education to improve land husbandry, encouragement of communities’ participation in natural resources management, sustaining life and livelihoods for the most vulnerable communities. These policies measures not only reduce sensitivity to drought, flood and soil erosion but also contribute to the improvement of households' adaptive capacities. Access to irrigation facilities enhances household farm asset base and reduces the risk of crop failure due to drought. Improving management of natural resources decreases the pressure on these resources and thereby diminishes the systems' sensitivity to climate and environmental hazards. Better access to agro-forestry and increased spending on education as well as creation of income opportunities for sustaining livelihood improve households' adaptive capacities. For effective uptake of these policy measures at sub-national level, the government should ensure that these national adaptation strategies effectively translate into specific local adaptation strategies that can be accessible and adopted by the community.

Although all districts analyzed in this research study may need such policy interventions, it is important to bring particular emphasis on Chikwawa, Machinga and Blantyre which were associated with the lowest index of vulnerability. In those districts with poor adaptive capacities and highly exposed to climate stress, government policies can also promote the development of index-based insurance, ensure access to climate forecast, early warning information and facilitate emergency assistance in the form of social safety nets including cash/food transfer. Attention should also been given to the improvement of women's livelihood through better access to productive assets and resources.

For future research, it will be important in addition to these primary data on households' perception to have secondary data on land quality in order to corroborate households' statements and better capture sensitivity to climate. In our study, the sensitivity dimension of the vulnerability index was based on household's perceptions of their land quality and experience with harvest failure.

Also, vulnerability is a dynamic concept and the research findings reflect the static 2009 snapshot of biophysical context and socio-economic conditions of households. So, the research findings might be sensitive to a change in those conditions. Of particular note was the devastating flood that hit severely many districts in central and southern Malawi in 2015 and caused major loss of household assets and livelihoods. This historical hazard may have change the spatial differentiation of vulnerability depicted in this study. It is therefore necessary to have a regular update of the indicators and analyzing the vulnerability dynamics for subsequent years is indispensable to reflect the bio-physical and economic changes in the profile of populations in southern Malawi.

\section{Acknowledgements}

The authors would like to acknowledge the United Nations Development Programme (UNDP) for providing support for this research under the Land Capability and Suitability project in the Lower Shire River Basin.

\section{References}

[1] FEWS NET (2015) Malawi Food Security Outlook Update, February, Lilongwe.

[2] Nangoma, E. (2007) National Adaptation Strategy to Climate Change Impact: A Case Study of Malawi. Human Development Report 2007/2008, 8 p.

[3] FAO (2010) Global Forest Resources Assessment 2010. Main Report. FAO Forestry Paper 163.

[4] (2011) Economic Analysis of Sustainable Resource Use in Malawi. UNDP Report, Lilongwe. 
[5] Cutter, S.L., Mitchell, J.T. and Scott, M.S. (2000) Revealing the Vulnerability of People and Places: A Case Study of Georgetown County, South Carolina. Annals of the Association of American Geographers, 90, 713-737. http://dx.doi.org/10.1111/0004-5608.00219

[6] Gbetibouo, G.A. and Ringler, C. (2009) Mapping South African Farming Sector Vulnerability to Climate Change and Variability: A Subnational Assessment. IFPRI Discussion Paper 00885, Washington DC.

[7] Piya, L., Maharjan, K.L. and Joshi, N.P. (2012) Vulnerability of Rural Households to Climate Change and Extremes: Analysis of Chepang Households in the Mid-Hills of Nepal. Selected Paper Prepared for Presentation at "The International Association of Agricultural Economists (IAAE) Triennial Conference,” Fozdo Iguacu, 18-24 August 2012.

[8] Vogel, C. and O’Brien, K. (2004) Vulnerability and Global Environmental Change: Rhetoric and Reality. Information Bulletin on Global Environmental Change and Human Security, No. 13. Environmental Change and Security Project and the International Development Research Centre, Ottawa.

[9] MMNRE (Ministry of Mines, Natural Resources and the Environment) (2006) Malawi’s National Adaptation Programmes for Action (NAPA). Ministry of Natural Resources and Environmental Affairs, Lilongwe.

[10] GOM (Government of Malawi) (2010) Malawi: Shire River Basin Management Project. Project Information Document, Concept Stage. Report No. AB 5365, Lilongwe.

[11] Sileshi, G. and Beedy, T. (2009) Land Capability and Suitability. Shire River Basin GEF Project, Draft Report, Lilongwe, $57 \mathrm{p}$.

[12] World Bank (2012) Shire River Basin Management Programme. Project Appraisal Document. World Bank, Washington DC.

[13] UNDP (2005) Sustainable Land Management and Climate Adaptation in the Shire River Basin. Project Development Facility. Request for PDFB/FSP. UNDP Initiation Document, Lilongwe, Malawi.

[14] Hebb, A. and Mortsch, L. (2007) Floods: Mapping Vulnerability in the Upper Thames Watershed under a Changing Climate. Final Report of the Canadian Foundation for Climate and Atmospheric Sciences (CFCAS) Project: Assessment of Water Resources Risk and Vulnerability to Changing Climatic Conditions.

[15] Gallopin, G.C. (2006) Linkages between Vulnerability, Resilience and Adaptive Capacity. Global Environmental Change, 16, 293-303. http://dx.doi.org/10.1016/j.gloenvcha.2006.02.004

[16] Hinkel, J. (2011) Indicators of Vulnerability and Adaptive Capacity. Towards a Clarification of the Science-Policy Interface. Global Environment Change, 21, 198-208. http://dx.doi.org/10.1016/j.gloenvcha.2010.08.002

[17] McCarthy, J.J., Canziani, O.F., Leary, N.A., Dokken, D.J. and White, K.S. (2001) Climate Change 2001: Impacts, Adaptation and Vulnerability. Cambridge University Press, Cambridge.

[18] Turner, B.L., Kasperson, R.E., Matson, P.A., McCarthy, J.J., Corell, R.W., Christensen, L., Eckley, N., HovelsrudBroda, G.K., Kasperson, J.X., Kasperson, R.E., Luers, A., Martello, M.L., Mathiesen, S., Naylor, R., Polsky, C., Pulsipher, A., Schiller, A. and Tyler, N. (2003) Illustrating the Coupled Human-Environment System for Vulnerability Analysis: Three Case Studies. Proceedings of the National Academy of the Sciences of the United States of America, 100, 8080-8085.

[19] Eriksen, S.H. and Kelly, P.M. (2006) Developing Credible Vulnerability Indicators for Climate Adaptation Policy Assessment. Mitigation and Adaptation Strategies for Global Change, 12, 495-524. http://dx.doi.org/10.1007/s11027-006-3460-6

[20] Cutter, S.L., Boruff, B.J. and Shirley, W.L. (2003) Social Vulnerability to Environmental Hazards. Social Science Quaterly, 84, 242-261. http://dx.doi.org/10.1111/1540-6237.8402002

[21] O’Brien, K., Leichenko, R., Kelkar, U., Venema, H., Aandahl, G., Tompkins, K., Javed, A., Bhadwal, S., Barg, S., Nyggard, L. and West, J. (2004) Mapping Vulnerability to Multiple Stressors: Climate Change and Globalization in India. Global Environmental Change, 14, 303-313. http://dx.doi.org/10.1016/j.gloenvcha.2004.01.001

[22] Moss, R.H., Brenkert, A.L. and Malone, E.L. (2001) Vulnerability to Climate Change. A Quantitative Approach. Report No. PNNL-SA-33642, Pacific Nortwest National Laboratory, Washington DC. http://www.ntis.gov/

[23] Adger, W.N. (1999) Social Vulnerability to Climate Change and Extremes in Coastal Vietnam. World Development, 27, 249-269. http://dx.doi.org/10.1016/S0305-750X(98)00136-3

[24] Nkondze, M.S., Masuku, M.B. and Manyatsi, A. (2013) Factors Affecting Households Vulnerability to Climate Change in Swaziland: A Case of Mpolonjeni Area Development Programme (ADP). Journal of Agricultural Science, 5, 108-122. http://dx.doi.org/10.5539/jas.v5n10p108

[25] Scoones, I. (1998) Sustainable Rural Livelihood: A Framework for Analysis. IDS Working Paper 72.

[26] Adger, W.N. (2006) Vulnerability. Global Environmental Change, 16, 268-281. http://dx.doi.org/10.1016/j.gloenvcha.2006.02.006

[27] Burton, I., Kates, R.W. and White, G.F. (1993) The Environment as Hazard. 2nd Edition, Guilford Press, New York. 
[28] Supin, W. and Loper, C. (2011) Indicators to Assess Community Level Social Vulnerability to Climate Change: An Addendum to SocMon and Em-Pasifika Regional Socio-Economic Guidelines. www.socmon.org/download.ashx?docid=64623

[29] Coulibaly, Y.J., Gbetibouo, G.A., Kundhlande, G., Sileshi, G.W. and Beedy, T.L. (2015) Responding to Crop Failure: Understanding Farmers' Coping Strategies in Southern Malawi. Sustainability, 7, 1-17. http://www.mdpi.com/2071-1050/7/2/1620 http://dx.doi.org/10.3390/su7021620

[30] Corbett, J. (2008) Famine and Household Coping Strategies. World Development, 16, 1099-1112. http://dx.doi.org/10.1016/0305-750X(88)90112-X

[31] Cherotich, V.K., Saidu, O. and Bebe, B.O. (2012) Access to Climate Change Information and Support Services by the Vulnerable Groups in Semi-Arid Kenya for Adaptive Capacity Development. African Crop Science Journal, 20, 169180.

[32] Fafchamps, M. and Minten, B. (2001) Returns to Social Network Capital among Traders. Oxford Economic Papers, 54, 173-206. http://dx.doi.org/10.1093/oep/54.2.173

[33] Knack, S. and Keefer, P. (1997) Does Social Capital Have an Economic Payoff? A Cross-Country Investigation. Quarterly Journal of Economics, 112, 1251-1288. http://dx.doi.org/10.1162/003355300555475

[34] Morrow, B.H. (1999) Identifying and Mapping Community Vulnerability. Disasters, 23, 11-18. http://dx.doi.org/10.1111/1467-7717.00102

[35] Adger, W.N. and Kelly, P.M. (1999) Social Vulnerability to Climate Change and the Architecture of Entitlements. Mitigation and Adaptation Strategies for Global Change, 4, 253-266. http://dx.doi.org/10.1023/A:1009601904210

[36] Cattell, R.B. (1978) The Scientific Use of Factor Analysis in Behavioral and Life Sciences. Plenum, New York.

[37] Filmer, D. and Pritchett, L.H. (2001) Estimating Wealth Effects without Expenditure Data—Or Tears: An Application to Educational Enrolments in States of India. Demography, 38, 115-131.

[38] Adger, W.N. and Vincent, K. (2005) Uncertainty in Adaptive Capacity. Comptes Rendus Geoscience, 337, 399-410. http://dx.doi.org/10.1016/j.crte.2004.11.004

[39] FEWS NET (2013) Malawi Food Security Outlook August 2012 to March 2013. FEWS NET, Lilongwe.

[40] Venema, J.H. (1991) Land Resources Appraisal of Ngabu Agricultural Development Division. Field Document No. 21. Land Resources Evaluation Project, Malawi Government Ministry of Agriculture, Land Husbandry Branch, UNDP, FAO.

[41] Malawi Vulnerability Assessment Committee (MVAC) (2010) Comprehensive Food Security and Vulnerability Analysis. MVAC, Lilongwe. 